\title{
Respiratory bellows-gated left atrial late gadolinium enhancement
}

Dana C Peters ${ }^{*}$, Benjamin R Knowles, Mehdi Hedjazi Moghari, Reza Nezafat, Warren J Manning

From 2011 SCMR/Euro CMR Joint Scientific Sessions

Nice, France. 3-6 February 2011

\section{Purpose}

To compare left atrial (LA) late gadolinium enhancement (LGE) imaging using bellows- and NAV-gating.

\section{Introduction}

The LGE method can visualize post-ablation scar in the LA, using increased spatial resolution (1-2). However, the inversion pulse required for LGE also nulls the liver signal at the time of data acquisition (optimal TI time), so that NAV-gating, used for respiratory compensation, becomes impossible. The NAV-restore (3), which reinverts the region of the liver immediately after the initial inversion pulse, permits gating. However, pulmonary vein $(\mathrm{PV})$ blood magnetization is also reinverted, and

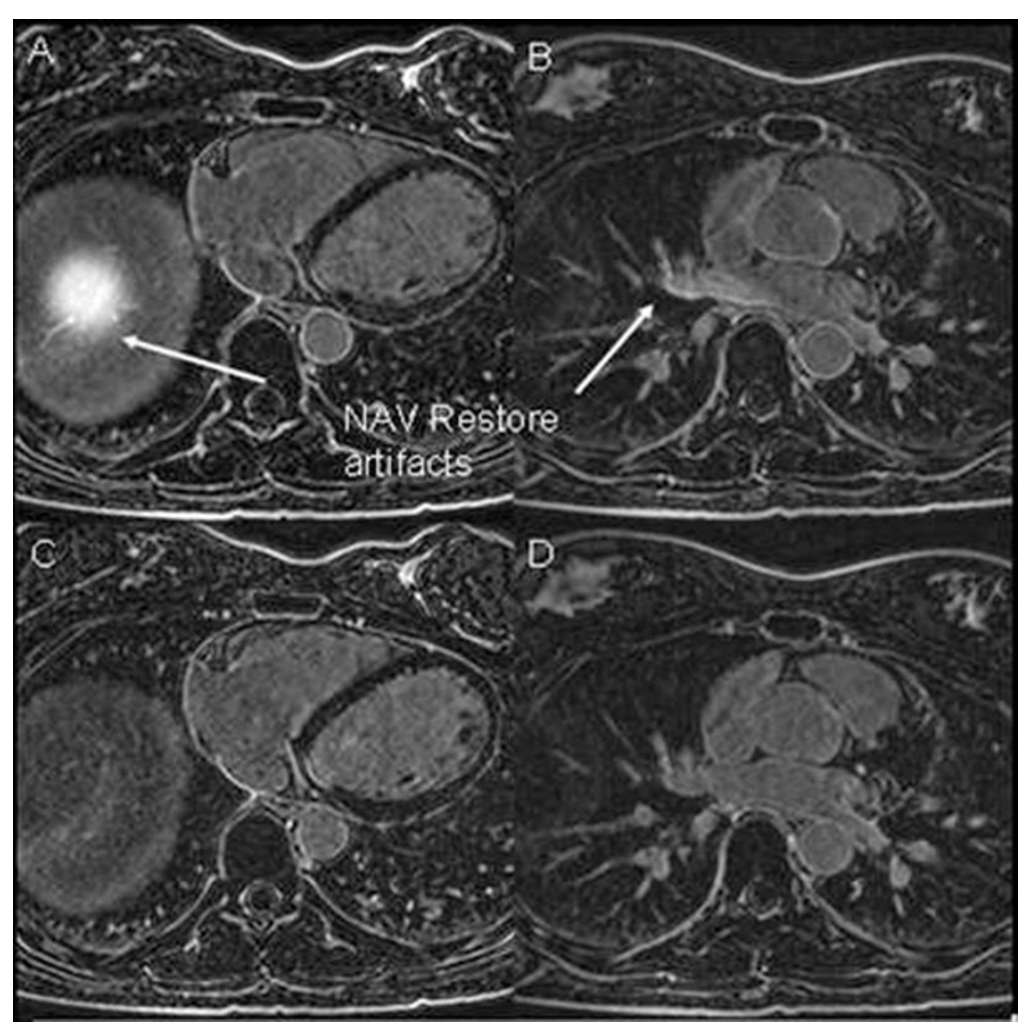

Figure 1 A, B) NAV-gated LA LGE, showing the NAV-restore artifacts on the liver (A), and in the right superior PV (B). C,D) Bellows gated LA LGE, with similar quality.

Beth Israel Deaconess Medical Center, Boston, MA, USA

(c) 2011 Peters et al; licensee BioMed Central Ltd. This is an open access article distributed under the terms of the Creative Commons 
flows into the left atrium, generating inflow artifacts. These artifacts have been addressed by 1 ) a NAV with a smaller diameter, 2) monitoring applied earlier before data acquisition (4), or directly after data acquisition (5), when the liver magnetization will be non-zero due to a shorter or longer effective TI (with no NAV restore needed). However, optimal NAV-gating demands monitoring coincident with acquisition of central k-space. Bellows-gating is an early respiratory compensation method, with recent data suggesting a strong correlation with the superior-inferior diaphragmatic motion (6-9). Here we present the results of bellows-gated LGE.

\section{Methods}

Nine healthy subjects $(5 \mathrm{~F}$, age $=26 \pm 14)$ were imaged in random order 15-25 minutes post contrast with identical 3D LGE sequences, using NAV-gating $(5 \mathrm{~mm}$ window with no tracking, with NAV prior to data acquisition) and commercially provided bellows-gating. The LA was imaged using an axial $(\mathrm{N}=6)$, or LV short-axis $(\mathrm{N}=3)$ orientation with parameters as previously described (1). Image sharpness and ghosting were evaluated on scale of 1-4 ( $4=$ excellent, $3=$ good, $2=$ fair, $1=$ poor); the appearance of inflow artifacts in the right PVs were noted $(0=$ none, $1=$ moderate, $2=$ severe $)$.

\section{Results}

Figure 1 compares bellows and NAV-gating. The average image sharpness was $3.0 \pm 0.5$ vs. $2.7 \pm 1.0$, with average ghosting of $3.1 \pm 0.8$ vs. $3.1 \pm 0.6$, for NAV and bellowsgating respectively $(\mathrm{p}=\mathrm{NS})$. For NAV-gating, the inflow artifacts affected the right superior PV, with an average grade of $1.7 \pm 0.4$ (severe), and the right inferior PV, with a grade of $0.7 \pm 0.4$ (moderate).

\section{Conclusions}

For 3D LGE LA imaging bellows-gating can provide similar respiratory compensation as the NAV, without inflow artifacts.

Published: 2 February 2011

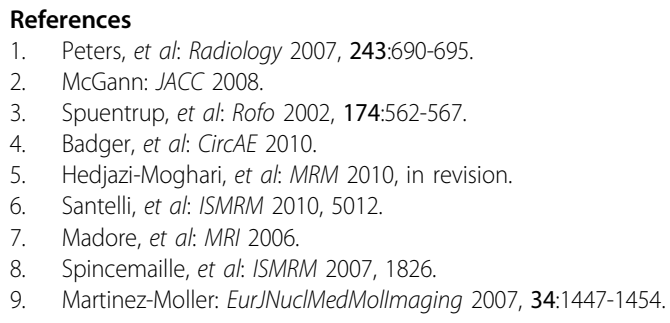

doi:10.1186/1532-429X-13-S1-P262

Cite this article as: Peters et al:: Respiratory bellows-gated left atrial late gadolinium enhancement. Journal of Cardiovascular Magnetic Resonance 2011 13(Suppl 1):P262.
Submit your next manuscript to BioMed Central and take full advantage of:

- Convenient online submission

- Thorough peer review

- No space constraints or color figure charges

- Immediate publication on acceptance

- Inclusion in PubMed, CAS, Scopus and Google Scholar

- Research which is freely available for redistribution 